\title{
Lesion by Focality
}

National Cancer Institute

\section{Source}

National Cancer Institute. Lesion by Focality. NCI Thesaurus. Code C48615.

A term referring to the number of anatomic sites affected by a disease. 